\title{
Study of $\mathrm{Rh} / \mathrm{TiO}_{2}-\mathrm{SiO}_{2}$ system in photolytic water splitting
}

\author{
Jolanta Wasilewska ${ }^{1} \cdot$ Michał Chmielarek $^{2} \cdot$ Wincenty Skupiński ${ }^{2}$ (]
}

Received: 11 September 2020 / Accepted: 28 December 2020 / Published online: 7 February 2021

(c) The Author(s) 2021

\begin{abstract}
Titania silicates $\left(\mathrm{TiO}_{2}-\mathrm{SiO}_{2}\right)$ of various compositions were prepared by a sol-gel method. $\mathrm{RhCl}_{3}$ was used in $0.2 \mathrm{wt} \%$ of $\mathrm{Rh}$ quantity on the gel surfaces, which were subsequently exposed to UV irradiation in water under a $355-\mathrm{W}$ UV lamp. $\lambda>370 \mathrm{~nm}$. Both Rh [I] and Rh [III] surface complexes were formed, depending on the gels composition. They also exhibited various efficiency in photo water splitting reaction, the photocatalysts possessing as supports titania-silica gels containing 40 and $50 \mathrm{~mol} \%$ of $\mathrm{TiO}_{2}$, were the most effective. According to our proposal, the rhodium complexes took part in the oxidative addition and reductive elimination cycle, where two water molecules in photo water splitting reaction, yielding hydrogen $-\mathrm{H}_{2}$ and two hydroxyl radicals. The two hydroxyls radicals, catalytically converted to oxygen atom and water, in the second cycle of the investigated water splitting reaction. Titanium octahedra and silicon tetrahedra linked by Ti-O-Si bridges were thought to be the grouping responsible for activity of the investigated catalysts. Their largest amounts are on the gels containing 40-58 mol $\% \mathrm{TiO}_{2}$.
\end{abstract}

Keywords $\mathrm{Rh} / \mathrm{TiO}_{2}-\mathrm{SiO}_{2}\left(\mathrm{TiO}_{2=} 0-100 \mathrm{~mol} \%\right) \cdot$ Photowater splitting reaction $\cdot$ Mechanism

\section{Introduction}

Titanium dioxide is well known as photocatalyst active in many processes e.g.: the environmental and energy fields, including self-cleaning surfaces, air and water purification systems, sterilization, hydrogen evolution, and photoelectrochemical conversion [1-4] but also as materials for photoeletrodes applied in water electrolysis, which is the most effective in solar water splitting processes [5-9]:

Wincenty Skupiński

wskupinski@ch.pw.edu.pl

1 Organic Technology and Catalytic Division, Faculty of Chemistry, Warsaw University of Technology, Noakowskiego 3, 00-664 Warsaw, Poland

2 High Energetic Materials Division, Faculty of Chemistry, Warsaw University of Technology, Noakowskiego 3, 00-664 Warsaw, Poland 
Its activity in these processes, is enhanced while determined metal or their oxide are deposed on its surface [10-12].

A very expressive example of $\mathrm{TiO}_{2}$ photocatalysts activation by metals, the systems $\mathrm{Ag}-\mathrm{TIO}_{2}$ possessing various amount of silver, may be [13].

It was applied to photo-decompose an OOL dye, under visible light. While the catalyst $\mathrm{Ag}, \mathrm{TiO}_{2}$, decomposed the dye, used in experiment quantity, almost completely, the bare $\mathrm{TiO}_{2}$ support decomposed only half.

Also such an effect can be reached while silicon atoms are incorporated to the titanium oxide lattice, while titania-silica and $\mathrm{TiO}_{2}$ were applied as photocatalysts in the water splitting reaction. The titania -silica containing $50 \mathrm{wt} \%$ could produce $25 \mu \mathrm{mol}$ of hydrogen/24 h, while only traces of hydrogen were determined, for titania, under the same experimental conditions [14]

In other work, when titania-silica gels of various compositions were investigated, the highest acidity and connected with it the highest efficiency in hydrogen oxide decomposition, were observed when the gel possessed $50 \mathrm{~mol} \%$ of $\mathrm{TiO}_{2}$ [15]

Deposition of metals on these mixed gels as: $\mathrm{Rh}, \mathrm{Ni}, \mathrm{Cr}, \mathrm{Co}, \mathrm{V}$, or their oxides yields effective catalysts in such reactions as benzene and $\mathrm{CO}$ hydrogenation, ethylene polymerization, reduction of $\mathrm{CO}$ by means of $\mathrm{NO}$, aldehyde condensation or oxidation of aromatic compounds [16].

Titania-silica gels $\left(\mathrm{TiO}_{2}-\mathrm{SiO}_{2}\right)$, obtained by wet hydrolysis of various hydrolysable compounds of titanium and silicon, feature a wide variety of physicochemical and structural properties, that depend on their composition, i.e. on the titanium and silicon content [14-19]. In all these gels Ti-O-Si bond occurs which bring in new, active, specific centers of an activity that exceeds the centers on the silica and titania gels alone.

However, electronegativity of these elements differ. For titanium it is 1.54 , for silicon, 1.90 [16]. Thus the silicon ion will be more electron-accepting in this bond which results in a shift of the electron cloud from titanium onto the oxygen ion and further on to silicon ion. This effect will be favored by an increased lability of titanium ion electrons than of silicon ion, as in the titanium ion the $3 p$ electrons are more distant from the nucleus than the $2 \mathrm{p}$ electrons in the silica ion (it will be more strongly attracted by the positively charged nucleus).

This will cause the titanium ion acquire properties of a relatively strong Lewis acid, the oxygen ion so the character of relatively strong Lewis base, whereas the silicon ion Lewis- acid properties will be reduced.

This acceptor effect depends on in what molecular structure the titanium ion will be in these mixed gels.

If the molar content of $\mathrm{TiO}_{2}$ in these gels does not exceed $10 \%$ the co-ordination number of the major amount of titanium ion equals four and only a minor amount of titanium ions ca. $10 \%$ have a co-ordination number six.

In tetrahedral structures oxygen ions are exposed on surfaces and in the case of silicate tetrahedral surface hydroxyl groups $-\mathrm{SiO}_{3}(\mathrm{OH}) 7^{4-}$ and in smaller amount of $-\mathrm{TiO}_{3}(\mathrm{OH}) 7^{4-}$ may occur. This ensures easier access of the particles interacting with them. The both hydroxyls posess specific IR bands: $3743 \mathrm{~cm}^{-1}$ (isolated Si-OH)) and $3615 \mathrm{~cm}^{-1}(\mathrm{Ti}-\mathrm{OH})$ [16], but after the gels annealing at temperature higher than $773 \mathrm{~K}$, only silanol groups remain. 
If the $\mathrm{TiO}_{2}$ content in gels is higher than $10 \mathrm{~mol} \%$, the quantity of octahedral titanium structures increases at the expense of the tetrahedral ones. The amount of the titanium octahedron-silica tetrahedron structures will predominate up to $50 \mathrm{~mol}$ $\% \mathrm{TiO}_{2}$ gels.

Also, structures with titanium ions of the co-ordination number five emerge. These are certainly located in surface beheaded octahedral and oxygen vacancies [12]. Also in this range of gel composition the Ti-O-Si grouping occur which bind titanium tetrahedra and octahedra with silicon tetrahedral.

After calcinations of these gels at temperatures higher than $773 \mathrm{~K}$ and their $\mathrm{TiO}_{2}$ content rises above $50 \mathrm{~mol} \%$, there appears the titanium oxide phase of anatase and rutile structures occur, about dimensions of $8-23 \mathrm{~nm}$, what destroys these gels lattice and dramatic decreases their specific areas [16, 18].

These data indicate that every composition of titania-silica gels will have its specific properties which may translate into their diversified physicochemical properties and applications.

The gels under consideration exhibit various acidity that primarily depends on composition and the annealing temperature during the preparation process [20]. The acidity is examined by a variety of techniques, mostly by the adsorption of basic indicators technique $[15,19]$. The recording of IR spectra of these adsorbed indicators, through measurements of the intensity and shifts of the positions of the suitable bands in the spectrum, allows to determine the amount and acid strength of the centers on surface of the gels under investigation.

The methods employed allowed to determine the amount of the acidic centers of the Brønsted and of the Lewis types. The quantity of these centers depends on the method of preparation of the gels under study and on the temperature of their calcinations [19]. Either of these centers were present in the highest number on the gels prepared by co-precipitation technique calcined at $350{ }^{\circ} \mathrm{C}$ and containing 44 to $92 \mathrm{~mol} \%$ titanium. The catalysts were tested in the reaction of dehydration of methanol to diethyl ether. In this reaction a relatively high activity was observed in the titanium oxide itself which possesses merely the Lewis-type acidic centers. However, the mixed-type titania-silica gels of the composition mentioned, with less Lewis-acid centers, but also with Brønsted acid centers, were more active. These gels were amorphous.

A rise of calcination temperature to $550{ }^{\circ} \mathrm{C}$ resulted in a decrease in the amount of both acidic centers in the catalysts under study and in a drop in their activity.

Titania-silica gels, as mentioned above, are also active in the photolytic reaction of decomposition of water to hydrogen and oxygen. Study on the catalyst of a composition $50 \mathrm{wt} \% \mathrm{TiO}_{2}-50 \mathrm{wt} \% \mathrm{SiO}_{2}\left(36 \mathrm{~mol} \% \mathrm{TiO}_{2}-64 \mathrm{~mol} \% \mathrm{SiO}_{2}\right)$, showed a higher effectiveness in this reaction than bare $\mathrm{TiO}_{2}$ [14].

The study made on this mixed gel, concerned with the following properties: band-gap energy, flat band potential, and doping density showed that the photocurrent density of $\mathrm{TiO}_{2}-\mathrm{SiO}_{2}$ mixed oxide is lower than that of bare $\mathrm{TiO}_{2}$ and the photocurrent density of $\mathrm{TiO}_{2}-\mathrm{SiO}_{2}$ mixed oxide is lower than that of bare $\mathrm{TiO}_{2}$. The data point to the excellent effectiveness of $\mathrm{TiO}_{2}-\mathrm{SiO}_{2}$, system in this photolytic reaction, to the higher flat band potential, band-gap energy, and doping density than those of bare $\mathrm{TiO}_{2}$. 
It has been postulated that the $\mathrm{Ti}-\mathrm{O}-\mathrm{Si}$ groupings are responsible for the high catalytic activity of these mixed gels. It should be also mentioned that the bridges will differ due to diversified environments, namely the $\mathrm{SiO}_{4}$ tetrahedron and the $\mathrm{TiO}_{6}$ octahedron. [16]

The various structures of titania-silica gels are likely to ensure, through specific interactions, various physico-chemical and catalytic properties of metal ions deposited on their surfaces [16].

When examining the system, namely rhodium ions deposited on titania-silica gels of various compositions: $0 \div 100 \mathrm{~mol} \% \mathrm{TiO}_{2}$, we wanted to determine how these gels would affect the physico-chemical and catalytic properties of rhodium ions deposited on them as well as their interaction in the photolytic water splitting reaction under investigation.

The results of these studies and the proposals of conversions taking place during the investigated reaction are presented in the paper below.

\section{Experimental section}

\section{Materials}

In the preparation procedure for titania-silica gels the following reagents were used: aqueous ammonia 25\% analytical purity grade (cz.d.a.) POCH Gliwice (Poland); Isopropyl alcohol cz.d.a., POCH Gliwice (Poland); Tetraethoxysilane, Sigma Aldrich, purified by distillation; Tetraethoxytitanium, 97\% purity, Sigma Aldrich. For the preparation of rhodium catalysts, rhodium (III) chloride hydrate (Rh, 38-40\%) (Sigma Aldrich) was used.

\section{Preparation of titania-silica gels}

Titania-silica gels were made, according to the literature data [14, 15] by wet hydrolysis of isopropanol solution of tetraethoxysilane and tetraethoxy titanate using $25 \%$ ammonia water as a precipitant in a suitable quantity of distilled water. Quantities of suitable amounts of these reagents to prepare theoretical compositions of particular gels are collected in Table 1.

Table 1 The amounts of tetraethoxy titanate and tetraethoxysilane required to make theoretical compositions of the titania-silica gels examined

\begin{tabular}{lllllllllllll}
\hline $\mathrm{TiO}_{2} / \mathrm{SiO}_{2}$ & $\mathrm{Mol} \%$ & $0 / 100$ & $10 / 90$ & $20 / 80$ & $30 / 70$ & $40 / 60$ & $50 / 50$ & $60 / 40$ & $70 / 30$ & $80 / 20$ & $90 / 10$ & $100 / 0$ \\
\hline$\left(\mathrm{C}_{2} \mathrm{H}_{5}\right)_{4} \mathrm{Ti}$ & $\mathrm{G}$ & 0 & 2.9 & 5.7 & 8.6 & 11.4 & 14.3 & 17.1 & 20.0 & 22.8 & 25.7 & 28.5 \\
$\left(\mathrm{C}_{2} \mathrm{H}_{5}\right)_{4} \mathrm{Si}$ & $\mathrm{G}$ & 34.6 & 23.4 & 20.8 & 18.2 & 15.6 & 13.0 & 10.4 & 7.8 & 5.2 & 2.6 & 0 \\
\hline
\end{tabular}




\section{Example description of the preparation of the $50 \mathrm{~mol}^{2} \mathrm{TiO}_{2}-50 \mathrm{~mol} \% \mathrm{SiO}_{2}$}

In a round-bottomed flask of a $500 \mathrm{~cm}^{3}$ capacity titanium tetraethoxide $(14.74 \mathrm{~g})$ and silicon tetraethoxide (13.00 g) were dissolved in $200 \mathrm{~cm}^{3}$ of isopropyl alcohol. The flask contents under a vigorous stirring was heated on a heating bowl until boiling. Then $7.8 \mathrm{~cm}^{3}$ ammonia water was added into the solution that made a white precipitate to form. Addition of a small amount of ammonia not to exceed $1 \mathrm{wt} \%$ suffices to make silicon hydroxide to precipitate completely.

The suspension thus obtained was vigorously stirred under a gentle boiling for one hour. Upon cooling of the reaction flask the precipitate was filtered off under a reduced pressure using a water-suction pump. Next, the product was washed several times with distilled water to rinse off the remainder of isopropanol and $\mathrm{HCl}$ (Ag test). The wet precipitate was fried successively for $24 \mathrm{~h}$ at three temperatures, i.e.: $333 \mathrm{~K}, 373 \mathrm{~K}$ and $423 \mathrm{~K}$. Upon comminution of the product on sieves down to $\mathrm{a}<0.04 \mathrm{~cm}$ fraction it was placed in a quartz vessel.

The titania-silica gel obtained was subjected to a calcining process for $24 \mathrm{~h}$ at $823 \mathrm{~K}$. Upon concluding all the processing stages the ready gel was stored in a desiccator with potassium hydroxide as a drying agent. Their specific areas were determined applying the BET method.

\section{Photocatalyst preparation [21]}

Solution $(9.5 \mathrm{mM})$ of $\mathrm{RhCl}_{3}$ in $30 \mathrm{~cm}^{3}$ distilled water was prepared. In a Schlenktype quartz round-bottomed flask $(50 \mathrm{ml}$ capacity) were placed: $1.08 \mathrm{ml}$ of prepared rhodium chloride solution and $0.55 \mathrm{~g}$ of the carrier. In an (air-conditioned), blackened, fume hood a flask was placed that was filled with a magnetically stirred suspension. The system was outgassed for 15 min under a pressure of 15 Torr. Subsequently, the system was exposed to the light from a POLAMP PLK-85 of a power rating of $355 \mathrm{~W}$ quartz lamp that emitted UV-VIS radiation for $8 \mathrm{~h}$ at a temperature of ca. $323 \mathrm{~K}$. The purpose of the light treatment was to make the rhodium settle from the solution on the carrier surface.

Upon catalyst photoactivation procedure the contents of the quartz flask was transferred to an evaporator. In the evaporator the whole water contained in the suspension was evaporated under a reduced pressure of 15 Torr. Thus, the photocatalyst ready for use in water photolysis was obtained.

The degrees of oxidation of so deposited rhodium compounds were determined by the ESCA method using ESCA VG ESCA-3 apparatus (internal reference standard $\mathrm{Ti} 2 \mathrm{p}_{3 / 2}=459.0 \mathrm{eV}$ ).

\section{Water photolysis reaction standard conditions}

Photoactivated catalyst $(0.05 \mathrm{~g})(0.2 \% \mathrm{Rh})$ was placed in a Schlenk quartz flask of a capacity of $50 \mathrm{ml}$ and was poured with $5.5 \mathrm{~cm}^{3}$ of re-distilled water maintaining a $\mathrm{pH}$ 7. In the flask a magnetic stirring element was placed and the system was 
degassed under vacuum of 15 Torr $(15 \mathrm{~min})$. The setup was placed in a ventilated, darkened fume hood. The water photolysis process was conducted for $24 \mathrm{~h}$ under stirring of the photocatalyst water suspension illuminating the system with a quartz lamp POLAMP PLK-85 UV-VIS of a power rating of $355 \mathrm{~W}$, at $326 \mathrm{~K}$.

The amount of the hydrogen evolved was determined by means of GLC (cathetometer, $20 \mathrm{~cm}$ column, $3 \mathrm{X}$ screens 1 , room temperature, helium as carrier gas.

\section{Results}

The specific surfaces of titania-silica gels obtained, their actual composition (by the ESCA method -Si2p signal intensity) and theoretical excess of the $\mathrm{SiO}_{2}$ and $\mathrm{TiO}_{2}$ phases are presented in Table 2

In order to confirm the composition of titania-silica gels obtained after their preparation, ESCA analysis as carried out as regards the quantity of silicon atoms in gel samples. The results of examination, presented in Table 2, indicate the excess silicon atoms from 2 to $6 \%$ in gels 10-50 Ti and lower quantity of these atoms for gels 60-90Ti ranging from 2 to $8 \%$. With this in mind, a decimal description of the symbols of the composition of gels will follow in the study.

The results of the ESCA analysis demonstrate that the calculated $\mathrm{SiO}_{2}$ and $\mathrm{TiO}_{2}$ phase excess values are also corresponding to their actual quantity in gels.

In titania-silica gels $\mathrm{Ti}-\mathrm{O}-\mathrm{Si}$ bonds are encountered, whereas $\mathrm{Si}-\mathrm{O}-\mathrm{Si}$ and $\mathrm{Ti}-\mathrm{O}-\mathrm{Ti}$ bonds appear only in appropriate excess phases. Taking this into consideration, Table 2 presents only excess phases depending on the composition of the gels obtained.

In a gel containing $10 \mathrm{~mol} \%$ of $\mathrm{TiO}_{2}$ (for the sake of simplicity, the individual compositions of investigated gels will be referred to as, for instance: $10 \% \mathrm{TiO}_{2}$ mol- $-90 \% \mathrm{SiO}_{2}$ mol, as $10 \% \mathrm{Ti}$, and the percentage values will always refer to molar percentages. Titanium ions of this oxide will form Ti-O-Si bonds-the titanium-silica phase and free $\mathrm{Si}-\mathrm{O}$ bonds in the silicate phase will theoretically $\mathrm{Si}$ bonds in the silicate phase will theoretically amount to $80 \mathrm{~mol} \%$. Excess of silicate phases decreases to zero for a $50 \%$ Ti gel.

When the $\mathrm{TiO}_{2}$ content increases to $60 \mathrm{~mol} \%$, the gel will still contain $40 \%$ of the titanium silica phase and $20 \%$ of the titanium oxide phase. While continuing to increase the amount of $\mathrm{TiO}_{2}$ in gels, the amount of $\mathrm{TiO}_{2}$ phase will increase to $80 \%$ for $90 \% \mathrm{TiO}_{2}$ gel, which still contains $10 \%$ of the titanium silica phase.

These calculations point to the fact that in titanium silica catalysts containing relatively high excess of $\mathrm{SiO}_{2}$ or $\mathrm{TiO}_{2}$, these phases can significantly affect the physico-chemical and catalytic properties of these catalysts.

The analysis of the surface of titania-silica gels obtained using the BET method revealed that the silica gel exhibited the largest specific surface area, namely 390 $\mathrm{m}^{2} / \mathrm{g}$; for $10 \% \mathrm{TiO}_{2}$ gel this surface is much smaller and amounts to $281 \mathrm{~m}^{2} / \mathrm{g}$. In other gels: $20-50 \% \mathrm{TiO}_{2}$, this area gradually decreases, from 266 to $196 \mathrm{~m}^{2} / \mathrm{g}$ with increased amount of titanium ions. The introduction of more Ti ions entails a significant change to the surface of their grains. These changes are not continuous: the $60 \%$ 


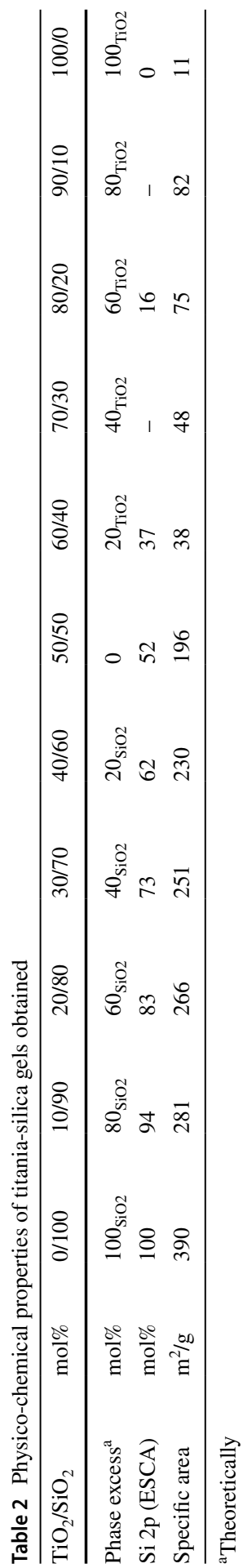


$\mathrm{TiO}_{2}$ gel exhibited the surface area equal to $38 \mathrm{~m}^{2} / \mathrm{g}$, and the $90 \% \mathrm{TiO}_{2}$ carrier: 82 $\mathrm{m}^{2} / \mathrm{g}$. $\mathrm{TiO}_{2}$ alone was characterized by the smallest specific surface area $=11 \mathrm{~m}^{2} / \mathrm{g}$.

These data indicate that the formation of $\mathrm{Ti}-\mathrm{O}-\mathrm{Si}$ bonds is accompanied by a proportional change in the specific surfaces of mixed oxides under investigation, within the range of 0-50Ti. According to model tests, these bonds connect the layers of chains of the phases [20]. As the surfaces of micropores share the greatest contribution to the overall surface of inorganic oxide grains, e.g.: 3 specific surfaces of microporous inorganic oxides amount to $1000 \mathrm{~m}^{2} / \mathrm{g}$, and for those macroporous oxides, the surfaces are contained in the range of $100-200 \mathrm{~m}^{2} / \mathrm{g}$, whereas pore diameters: amount to 1-2 $\mathrm{nm}$ and over $50 \mathrm{~nm}$ [22]. Thus, in the excess $\mathrm{SiO}_{2}$ phases, Ti-O-Si bonds separate off the micropores that occur in the silica gel and entice a gradual decrease of specific surface area of 90-40Ti gels. Therefore, Ti-O-Si bonds are likely to block the entry to these pores.

$50 \% \mathrm{Ti}$ gel consists only of the titanium silica phase: $\mathrm{TiO}_{2}$ octahedron - $\mathrm{SiO}_{2}$ tetrahedron, with a specific surface area of $196 \mathrm{~m}^{2} / \mathrm{g}$.

When a separate amorphous titanium oxide phase is present in titania-silica gels, then, during annealing above $773 \mathrm{~K}$, as mentioned earlier, this phase is initially converted into the rutile crystalline form, and then into anatase crystals. This process is accompanied by the decrease of the surface area of such gels and the destruction of their surface forms [15, 23].

Crystals are usually characterized by relatively small specific surfaces and if they appear on the surfaces of investigated gels, they need to reduce their surface significantly, proportionally to the increased $\mathrm{TiO}_{2}$ phase content. However, in the case under study no proportionality between the amount of $\mathrm{TiO}_{2}$ in gels and the specific surface area was observed, namely the $60 \% \mathrm{TiO}_{2}$ gel has a surface area of $38 \mathrm{~m}^{2} / \mathrm{g}$, and $90 \% \mathrm{TiO}_{2}$ gel: $84 \mathrm{~m}^{2} / \mathrm{g}$.

In a $60 \% \mathrm{TiO}_{2}$ gel, the phase composed of $\mathrm{TiO}_{2}$ octahedrons and $\mathrm{SiO}_{2}$ tetrahedra still occupies a significant area. The grains containing $50 \% \mathrm{TiO}_{2}$ have a specific surface area of $196 \mathrm{~m}^{2} / \mathrm{g}$ and $60 \% \mathrm{TiO}_{2}$ gel should be expected to have a slightly lower surface area. Presumably, the crystallization of $20 \% \mathrm{TiO}_{2}$ to anatase proceeds with closed micropores of the titanium silica phase, possibly by blocking the entries to these pores with anatase crystals. Their dimensions extend from 8 to $23 \mathrm{~nm}$ [23], and the entries to the micropores amount to $2 \mathrm{~nm}$. The nucleation and formation of crystals is also taking place at "hot spots" on solid surfaces, namely the edges of surface layers [24], for instance, pore entry points and the running anatase crystallization yields the described effect.

The relatively large specific surface of the $90 \% \mathrm{TiO}_{2}$ gel probably is the result of the construction of a relatively large number of anatase crystals of large dimensions, only at the expense of the $\mathrm{TiO}_{2}$ phase itself and the exposure of the titanium silica phase.

The absence of this phase in $\mathrm{TiO}_{2}$ alone must have resulted in correspondingly large anatase crystals of specific surface area of $11 \mathrm{~m}^{2} / \mathrm{g}$.

These effects work together in other gels in this range, producing diversified specific surface areas.

The acidity tests of the obtained titania-silica gels by Hammett indicators method revealed poor acidic properties of gels amounting to $\mathrm{H}_{\mathrm{O}=} \leq+2.8$ strength. It 
corresponds to the $0.002 \%$ of acid strength of sulfuric acid. This method does not distinguish between the character of Brønsted-type acid centers and Lewis-type acid centers.

Lewis-type acid surface catalytic centers may accept one or two electrons from donor compounds [25]. The application of a single-electron donor terylene adsorption in the investigation aimed to determine the actual character of acid centers of the gels under study. The results of these tests are presented in Table 3.

The results obtained exhibit a corresponding quantity of both centers depending on the composition of investigated gels, within the range of $0 \div 50 \% \mathrm{TiO}_{2}$, with a maximum value for $40-50 \% \mathrm{TiO}_{2}$ for gels. For higher $\mathrm{TiO}_{2}$ content in gels, the centers of $\mathrm{H}_{\mathrm{o}} \leq+2.8$ strength are absent, however they continue to demonstrate the presence of single electron acceptor centers. This indicates that in such cases the Lewistype acid centers are available for perylene molecules, but no longer available for the thymol blue indicator $\mathrm{H}_{\mathrm{o}} \leq+2.8$. This is probably the result of the differences in the structure of these indicators [26] (Fig. 1).

Perylene is a flat arrangements of four aromatic rings, whereas thymol blue constitutes a three aromatic ring system, however numerous substituents enhance the surface area of the entire molecule making it uneven.

In both cases, the greatest quantity is encountered when the gels contain 40 and $50 \% \mathrm{TiO}_{2}$. This indicates that the surface acid centers on investigated gels are of Lewis acid character, located on the surface Ti [IV] ions.

The conducted IR examination revealed the presence of the $3748 \mathrm{~cm}^{-1}$ band characteristic for the isolated silanol group $\equiv \mathrm{Si}-\mathrm{OH}[13,16]$.

\section{Surface complexes of rhodium applied to $\mathrm{TiO}_{2}-\mathrm{SiO}_{2}$ gels}

In aqueous $\mathrm{NaOH}$ solutions, $\mathrm{RhCl}_{3}$ is converted to yellow trihydrate trihydroxy rhodium [III] $\mathrm{Rh}(\mathrm{OH})_{3} 3 \mathrm{H}_{2} \mathrm{O}$ (reaction 1):

$$
\mathrm{RhCl}_{3} \cdot 3 \mathrm{H}_{2} \mathrm{O}+3 \mathrm{NaOH} \rightarrow \mathrm{Rh}(\mathrm{OH})_{3}+3 \mathrm{H}_{2} \mathrm{O}+3 \mathrm{NaCl}
$$

Formally, it constitutes a typical reaction of hard acids and bases [27]: sodium cation and chloride anion as well as soft acids and bases; Rh cation [III] and hydroxyl anion. This reaction runs successfully in the presence of inorganic oxides, as the hydroxide is unstable and its interaction with the surface groups of these oxides stabilizes the hydroxide [28]. The enthalpy of this interaction is negative $\left(\Delta \mathrm{H}_{3}\left(\mathrm{~kJ} \mathrm{~mol}^{-1}\right)\right.$ for the following mixed oxides: $\mathrm{Ca}_{2} \mathrm{Nb}_{3} \mathrm{O}_{10}(-35), \mathrm{KNb}_{6} \mathrm{O}_{17}(-37)$, $\mathrm{Rb} 0 . \mathrm{TaO}_{3}(-32)$, and for $\gamma-\mathrm{Al}_{2} \mathrm{O}_{3}$ and $\mathrm{SiO}_{2}$ these enthalpies have positive values of 55 and 25, respectively. Negative enthalpies indicate fairly strong $\mathrm{Rh}(\mathrm{OH})_{3}$ carriers. However, this hydroxide deposited on aluminum oxide is stable to the degree allowing to be used as a catalyst in the transformation of aldehydes to primary amides reaction [29].

Another way to obtain trihydroxy rhodium deposited on the surface of inorganic carriers involves depositing of $\mathrm{RhCl}_{3}$ on a given carrier in water and then exposing it to UV light $[21,30]$. 


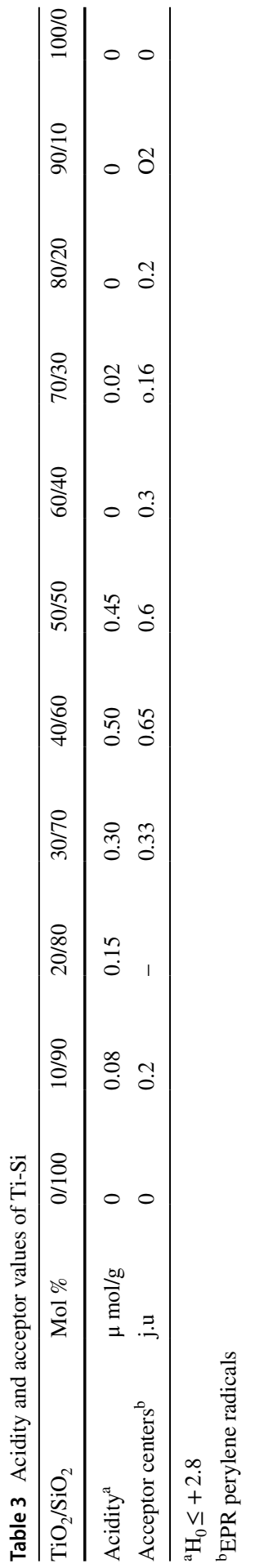


Fig. 1 The structure of indicator used

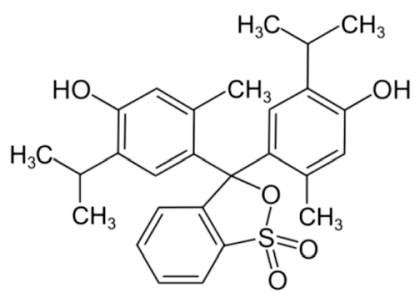

thymol blue<smiles>c1cc2cccc3c4cccc5ccc6cccc(c(c1)c23)c4c65</smiles>

perylene

If the driving force in the production of $\mathrm{Rh}(\mathrm{OH})_{3}$ from $\mathrm{RhCl}_{3}$ in the presence of weak bases is the formation of $\mathrm{NaCl}$, then the production of $\mathrm{Rh}(\mathrm{OH})_{3}$ from $\mathrm{RhCl}_{3}$ in water in UV light is taking place due to the energy contributed to $\mathrm{RhCl}_{3}$ by this radiation (reaction 2 ):

$$
\mathrm{RhCl}_{3}+3 \mathrm{H}_{2} \mathrm{O}+\mathrm{h} \gamma \rightarrow \mathrm{Rh}(\mathrm{OH})_{3}+3 \mathrm{HCl}
$$

These hydroxides were formed on $60-100 \mathrm{TiO}_{2}$ carriers, as the presence of $\mathrm{Rh}$ [III] ions was detected on them by ESCA method (Table 4).

The $\mathrm{HCl}$ yielded in reaction 2 , under the conditions of the photocatalyst preparation, cannot become adsorbed on their surfaces due to strongly adsorbed water, and additionally, hydrogen chloride is vigorously complexed with water molecules, thus hindering a possible reversible reaction [31]. Washing photocatalysts obtained with water removes resulting $\mathrm{HCl}$ effectively.

However, the ESCA method enabled to detect the presence of rhodium [I] compounds on $0-50 \% \mathrm{TiO}_{2}$ carriers and on $60-90 \% \mathrm{Ti}$ carriers next to $\mathrm{Rh}[\mathrm{III}]$ ions.

The syntheses of rhodium [I]: $\mathrm{RhCl}(\mathrm{PPh} 3) 3$ and $\mathrm{Rh} 2 \mathrm{Cl} 2$ (C2H4) 4 complexes, described in the literature $[32,33]$ were carried out in excess of phosphine or olefin. In the products, in addition to the rhodium [I] complexes, $\mathrm{HCl}$ and oxidized forms of phosphine or olefin as well as water (reactions 3 and 4) were found in reaction products.

$$
\begin{gathered}
\mathrm{RhCl}_{3}\left(\mathrm{H}_{2} \mathrm{O}\right)_{3}+4 \mathrm{PPh}_{3} \rightarrow \mathrm{RhCl}\left(\mathrm{PPh}_{3}\right)_{3}+\mathrm{OPPh}_{3}+2 \mathrm{HCl}+2 \mathrm{H}_{2} \mathrm{O} \\
2 \mathrm{RhCl}_{3}\left(\mathrm{H}_{2} \mathrm{O}\right)_{3}+6 \mathrm{C}_{2} \mathrm{H}_{4} \rightarrow \mathrm{Rh}_{2} \mathrm{Cl}_{2}\left(\mathrm{C}_{2} \mathrm{H}_{4}\right)_{4}+2 \mathrm{CH}_{3} \mathrm{CHO}+4 \mathrm{HCl}+4 \mathrm{H}_{2} \mathrm{O}
\end{gathered}
$$

The water molecule from the co-ordination sphere $\mathrm{RhCl}_{3} 3 \mathrm{H}_{2} \mathrm{O}$ must be the source of hydrogen and oxygen in this reaction. Two chlorines from two $\mathrm{HCl}$ molecules must originate from $\mathrm{RhCl}_{3}$ molecule, and two electrons to reduce $\mathrm{Rh}$ [III] to $\mathrm{Rh}[\mathrm{I}]$ from $\mathrm{Rh}-\mathrm{Cl}$ bonds. These effects should result from the following conversions.

The phosphine or ethylene molecules, as strong complexing agents, displace water molecule from the co-ordination sphere of rhodium [III]. The complexes with the possibility of forming "back donation" effect [34, 35], where two electrons of these ligands are located on the vacant 4d-orbital of the rhodium ion [III], and two electrons fill the $4 \mathrm{~d}$-orbital of this ion, shift to the vacant anti-bonding orbital of 


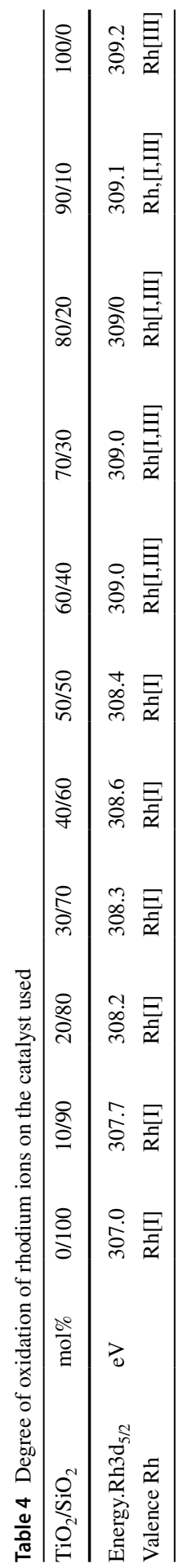


phosphine or ethylene, are likely to yield such changes in the rhodium ion electron environment that affords a hemolytic degradation of two $\mathrm{Rh}-\mathrm{Cl}$ bonds while forming two chloride radicals and two electrons already located on the rhodium ion [I]. Two chloride radicals attack another molecule of coordinated water, forming two $\mathrm{HCl}$ molecules and atomic oxygen. The oxygen attacks the complexed phosphine to form its oxide $\mathrm{OPPh}_{3}$ and converts the complexed olefin to an aldehyde. Both products are no longer characterized by such complexing properties as phosphines and olefins and leave the co-ordination sphere of rhodium ions. These released co-ordination sites are filled by "stoichiometric" phosphines or olefins.

These conversions are specific due to the ligands forming the "back donation" effect, as for instance, $\mathrm{H}_{2} \mathrm{O}$ ligands, which do not bring about such effects, fail do reduce $\mathrm{Rh}[\mathrm{III}]$ ions to $\mathrm{Rh}[\mathrm{I}]$ ions.

On the other hand, in $\mathrm{RhCl}_{3}$ applied onto investigated gels: $\mathrm{SiO}_{2}$ and $10-90 \% \mathrm{Ti}$ carriers with $\mathrm{Ti}-\mathrm{O}-\mathrm{Si}$ bonds, in an aqueous solution during irradiation with UV rays leading to the trihydroxyrhodium product [III], the Rh ion [III] undergoes reduction to $\mathrm{Rh}$ ion [I]. This reaction was running in the absence of organic compounds.

Thus, the reduction of Rh [III] ions needs to run only through the homolytic cleavage of two Rh-OH bonds, yielding $\mathrm{Rh}[\mathrm{I}]$ ion and two hydroxyl radicals:

$$
2 \mathrm{Rh}(\mathrm{OH})_{3}+\mathrm{h} v \rightarrow 2 \mathrm{Rh}[\mathrm{I}] \mathrm{OH}+4 \cdot \mathrm{OH}
$$

For homogeneous homologues of rhodium [I] complex obtained, dimeric [X (cyclooctadiene) rhodium (I) $]_{2}$ complexes, where $\mathrm{X}=\mathrm{Cl}_{\mathrm{NH}}$ and $\mathrm{OCH}_{3}$, the determined bond lengths and angles between them differed slightly, depending on the $\mathrm{X}$ ligands, however were contained in the following ranges: $\mathrm{Rh}-\mathrm{O} \sim 2.1 \AA$ bonds, $\mathrm{Rh}-\mathrm{Rh}$ bond length $=2.8 \div 3.3 \AA$, and $\mathrm{X}-\mathrm{Rh}-\mathrm{X}=86^{\circ} \div 90^{\circ}$ for angles, $\mathrm{Rh}-\mathrm{H}_{2} \mathrm{O}$ distance $\sim 2.2 \AA$ [36-38].

In the investigated carriers, the titanium oxide phases have octahedral anatase structures, where the Ti-O bond length is $\sim 2.0 \AA$, $\mathrm{O}-\mathrm{O}$ equatorial $=\sim 2.8 \AA$ [39]. In the silica phases, the length of $\mathrm{Si}-\mathrm{O}$ bonds amounts to $\sim 1.6 \AA$ [40].

These bond and angular lengths should appear on the obtained rhodium [III] and rhodium [I] surface complexes.

Heating of the investigated titanium-silica gels at $823 \mathrm{~K}$ aimed at stabilizing the oxide structures of mixed gels and silica gel, titanium oxide.

Under these conditions, the titanium oxide is primarily converted to anatase and to rutile, in lower quantities. In these structures, truncated oxide octahedrons appear on their surface, where four oxygen anions are located at equatorial positions, with in-between detected titanium ion IV]. These octahedrons are interlinked through their edges.

In the silica gel, $\mathrm{OH}$ vicinal groups $-\mathrm{Si}(\mathrm{OH})-\mathrm{O}-\mathrm{Si}(\mathrm{OH})-$, geminal $=\mathrm{Si}(\mathrm{OH})_{2}$ and isolated $\equiv \mathrm{Si}-\mathrm{OH}[40]$ will appear on its surface.

In titania-silica gels, where the octahedron titanium oxide - silicon oxide tetrahedron groups are present, these structures are connected by Ti-O-Si bonds.

On tetradra surface, the silica will be bound to truncated octahedrons of titanium oxide and only isolated $\mathrm{OH}$ groups bound to silicon ion, oxygen anions of Ti-O-Si bonds and exposed titanium ions [IV] will appear on their surface [16]. 
The rhodium ions [III] in complex compounds most often adopt the octahedron structures by binding six ligands with $\pi$ and $\sigma$ bonds. The electron configuration of $4 \mathrm{~d}$-rhodium in these complexes is $\mathrm{d}^{6}$. The rhodium ion [I] in complex compounds most often adopt the structures of a flat square by binding four ligands with $\pi$ i $\sigma$ bonds. The electron configuration of $4 \mathrm{~d}$-rhodium in these complexes is $\mathrm{d}^{8}$ [41].

In investigated systems, $\mathrm{Rh}[\mathrm{III}](\mathrm{OH})_{3}$ on $\mathrm{TiO}_{2}$ phases, these hydroxides must be complexed with three non-bonding electron pairs on the surface oxygen orbitals to form octahedral structure. In the case of Rh [I] OH complex, it must be co-ordinated by three non-bonding electron pairs on the surface oxygen orbitals to form a flat square structure.

These data were employed for proposing the following models of the obtained surface rhodium complexes-Fig. 2.

In the model $\mathrm{Rh}(\mathrm{OH})_{3}$ /anatase system in the octahedral rhodium complex, two $\mathrm{TiO}_{2}$ oxygen anions and two trihydroxy rhodium trihydroxy anions appear in equatorial positions, whereas one $\mathrm{TiO}_{2}$ oxygen anion and one rhodium trihydroxy hydroxyl anion in axial positions.

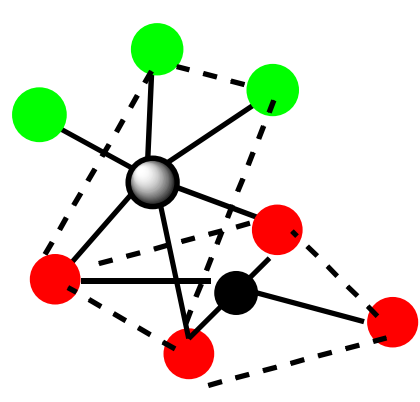

$\mathbf{a}$

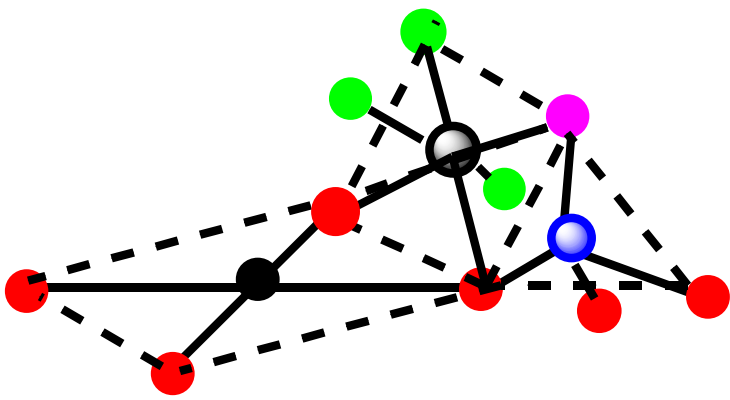

b

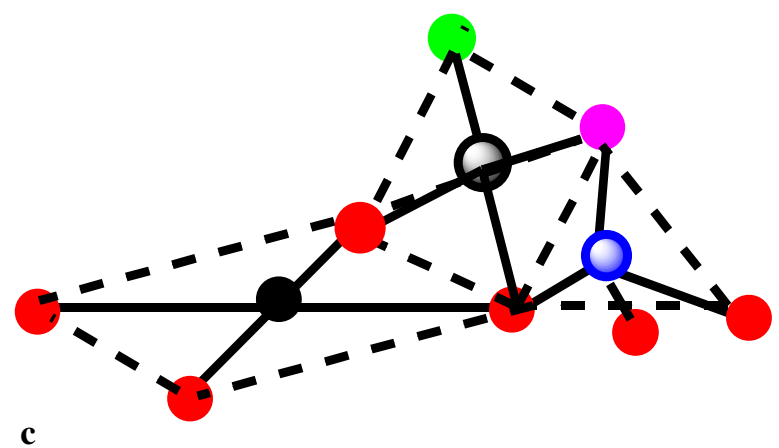

Fig. 2 Suggested models: a $\mathrm{Rh}[\mathrm{III}](\mathrm{OH})_{3}$ deposited on anatase crystal; $\mathbf{b} \mathrm{Rh}[\mathrm{III}](\mathrm{OH})_{3}$ on the surfaces of titania-silica phases; $\mathbf{c} \mathrm{Rh}[\mathrm{I}]$ complex on the surfaces of titania-silica phases. Colours: red balls oxygen anions bound with titanium ion; black balls titanium ions, silver balls rhodium ions, green balls hydroxyl anions bound with rhodium ion, blue ball silicon ion, yellow ball hydroxyl anion bound with rhodium ion, purple ball hydroxyl anion bound with silicon ion. Dotted lines demonstrate square planes on the surface of anatase and amorphous $\mathrm{TiO}_{2}$ as well as in rhodium complexes 
In octahedral rhodium complexes deposited on the surfaces of titania-silica $50 \% \mathrm{Ti}$ carriers, two oxygen anions of $\mathrm{TiO}_{2}$, one oxygen anion of the hydroxyl group bound with silicon ion and one anion of the hydroxyl group of the trihydroxy rhodium appear in equatorial positions. The remaining two hydroxyl groups of this hydroxide are located in axial positions.

The rhodium ion [III] has the $\mathrm{d}^{6}$-electron configuration in the complex of octahedron structure and when all electron spins are paired in this system (low spin configuration), the Jahn-Teller effect is taking place. In such a complex, if the ligands are of a donor character, then the lengths of metal-axial ligand bond will be elongated, and such deformation is trigonal. This results in splitting of the $\mathrm{e}_{\mathrm{g}}$ orbital with two electrons located on the lower $\mathrm{d}_{\mathrm{z}}{ }^{2}$ orbital.

Investigated rhodium [III] trihydroxy surface complexes complexed with three surface donor oxygen of the carrier should be in such situation model b, Fig. 2. In this model, two Rh-OH bonds are in axial positions.

In the model complex of rhodium [I] c-structure, two oxygen donor $\mathrm{TiO}_{2}$ ions are in equatorial positions; one donor oxygen anion of the hydroxyl group bound with silicon ion, and one hydroxyl anion.

In rhodium [I] complexes of $\mathrm{ML}_{4}$ flat square structure [34, 35, 42], the $\mathrm{dz}^{2}$-orbital is characterized by a higher energy than the $\mathrm{d}_{\mathrm{zy}}$ and $\mathrm{d}_{\mathrm{zx}}$ orbitals, however the energy is lower than in the case of $d_{x y}$ orbital, whereas the $\mathrm{d} \mathrm{x}^{2}-\mathrm{y}^{2}$ orbital has such a high energy that it hinders electron from being shifted from lower d-orbitals. This facilitates transferring the electrons from lower orbitals to adequately low energy anti-bonding ligand orbitals, whilst maintaining orbital symmetry. It is favored by donor ligands.

Such a situation should take place in the resulting surface rhodium hydroxyl complexes [I].

In all model rhodium complexes, hydroxyl groups are bonded with rhodium ions by $\sigma$-bonds, whereas the remaining bonds are coordinating ones.

In the case of the $\mathrm{Rh}(\mathrm{OH})_{3}$ /anatase system, the equatorial $\mathrm{Rh}-\mathrm{O}$ bonds and $\mathrm{Rh}-\mathrm{O}$ axial bonds, due to the tight crystal lattice of the carrier, will have difficulties in elongation, as ensured by Jahn-Teller effect [33-35].

Each two hydroxyl groups in this structure are located in cis positions. Such a grouping in the ruthenium pincer complexes, according to D. Milstein [43], is a transition complex towards this catalyst, in the photolytic water splitting reaction into hydrogen and oxygen. Such system is also mentioned in the theoretical considerations by W. E. Piers [44] on the reaction towards transition metals.

Taking into the account the previously mentioned lengths of bond and angles in the olefinic complexes of rhodium [I] as well as the proposed structures of investigated rhodium [III] and rhodium [I] surface complexes: a, b, and c; the specific surface areas of the carriers and the Avogadro number, it was possible to perform calculation of surface areas occupied by examined complexes on relevant carriers.

The calculated surface areas of rhodium [III] complexes amount to $\sim 30 \AA^{2}$ : for two truncated octahedrons on $\mathrm{TiO}_{2}$.

For truncated $\mathrm{TiO}_{2}$ and $\mathrm{SiO}_{2}$ tetrahedron, the surface area of rhodium [III] complexes amounts to $\sim 25 \AA 2$. 
The amount of $\mathrm{RhCl}_{3}$ applied per gram of carrier $=610^{-6} \mathrm{~mol} / \mathrm{g}$ and on the selected specific surface areas of the carrier was used for calculating the surface concentrations of rhodium complexes. For the $\mathrm{Rh} 50 \% \mathrm{TiO}_{2}$, this concentration amounted to $0.14 \mathrm{~mol} \%$, for $\mathrm{SiO}_{2}-0.09 \mathrm{~mol} \%$, whereas for $\mathrm{TiO}_{2}=2 \mathrm{~mol} \%$.

This indicates that the carrier surface constitutes the dominant area of the photocatalysts obtained and its properties must add to the properties of rhodium centers.

\section{Water photolysis}

The study of photolytic water splitting reaction against the examined photocatalysis yielded the following results, as presented in Table 5.

The obtained quantity of hydrogen in the examined reactions demonstrate that the rhodium [I] complexes deposited on the surface of amorphous silica gel exhibit a relatively poor activity.

The rhodium [III] complexes deposited on the anatase surface exhibit a comparable low activity. The $\mathrm{SiO}_{2}$ carrier itself demonstrated no activity, whereas the anatase - only a slight amounts.

In the carriers containing from 10 to $30 \mathrm{~mol}^{2} \mathrm{TiO}_{2}$, the dominant phase belongs to amorphous silica gel, which barely activates rhodium complexes, however a slight increase in hydrogen yield is attributable to the increasing number of Ti-O-Si bonds.

In turn, in the $40-50 \% \mathrm{TiO}_{2}$ carriers, the titanium-silica phase is dominant, which is made up of $\mathrm{TiO}_{2}$ octahedrons and $\mathrm{SiO}_{2}$ tetrahedra linked by Ti-O-Si bridges. These systems activate rhodium [I] complexes fairly strongly, which are deposited on these carriers, on the $50 \% \mathrm{TiO}_{2}$ carrier in particular.

In the carriers containing 60-90\% $\mathrm{TiO}_{2}$, increasing quantites of anatase crystals inactivating the rhodium [III] complexes are introduced to the titanium silica phase, however the remaining surface areas of the titanium-silica phases ensure a relatively high activity of investigated photocatalysts, although they decrease with the increasing amount of $\mathrm{TiO}_{2}$ in the carriers.

As mentioned earlier, the rhodium [I] complexes occupy a tiny part of the carrier surface areas and the possible catalytic properties of a given carrier may add to the activity of the rhodium centers. To verify this, water splitting studies were carried out in standard conditions in the presence of the $50 \% \mathrm{TiO}_{2}$ carrier, the most effective photocatalytic system. We obtained $0.20 \mathrm{~cm}^{3}$ of hydrogen.

Slightly higher yields $\left(0.028 \mathrm{~cm}^{3} / \mathrm{g}\right.$ cat., $\left.24 \mathrm{~h}\right)$ were obtained by testing the photolytic water splitting reaction on mixed titania-silica gels.

Table 5 Quantity of the hydrogen against the $\mathrm{Rh} / \mathrm{TiO}_{2}-\mathrm{SiO}_{2}$ photocatalysts obtained

\begin{tabular}{lllllllllllll}
\hline $\mathrm{TiO}_{2}$ content & $\mathrm{mol} \% \mathrm{TiO}_{2}$ & 0 & 10 & 20 & 30 & 40 & $50 *$ & 60 & 70 & 80 & 90 & $100^{* *}$ \\
\hline Hydrogen amount & $\mathrm{cm}^{3} \mathrm{H}_{2} / \mathrm{g}_{\text {cat }}$ & 0.02 & 0.4 & 0.6 & 0.4 & 4.6 & 5.4 & 1.3 & 1.0 & 0.8 & 0.2 & 0.02 \\
\hline
\end{tabular}

$* 0.02 \mathrm{~cm}^{3} / \mathrm{g}_{\text {cat }}$ of hydrogen against the $50 \mathrm{~mol} \% \mathrm{TiO}_{2}-50 \mathrm{~mol} \% \mathrm{SiO}_{2}$ carrier examined 
Thus, in the case of the most effective photocatalyst tested, $5.38 \mathrm{~cm}^{3}$ of water converted on rhodium [I] complexes, and $0.02 \mathrm{~cm}^{3}$ - on the centers on the carrier surface $50 \%$ of $\mathrm{TiO}_{2}$. This indicates that rhodium centers are 270 times more active.

The oxygen vacancies feature the centers of water photolysis on $\mathrm{TiO}_{2}$ and mixed titania-silica gels $[14,45]$. They result from the release of atomic oxygen from the surface bridges: $\mathrm{Ti}-\mathrm{O}-\mathrm{Ti}$ and $\mathrm{Ti}-\mathrm{O}-\mathrm{Si}$ when exposed to UV radiation Reactions 6-9.

$$
\begin{gathered}
\mathrm{Ti}-\mathrm{O}-\mathrm{Ti}+\mathrm{h} v \rightarrow \mathrm{Ti}^{3+} \cdot \mathrm{Ti}^{3+}+\mathrm{O} \\
\mathrm{Ti}^{3+} \cdot \mathrm{Ti}^{3+}+\mathrm{H}_{2} \mathrm{O} \rightarrow \mathrm{H}_{2}+\mathrm{Ti}-\mathrm{O}-\mathrm{Ti}
\end{gathered}
$$

Summy: $\mathrm{TiO}_{2}+\mathrm{h} v \rightarrow \mathrm{H}_{2}+\mathrm{O}$

$$
\begin{aligned}
& \mathrm{Ti}-\mathrm{O}-\mathrm{Si}+\mathrm{h} v \rightarrow \mathrm{Ti}^{2+} \cdot \mathrm{Si}^{4+}+\mathrm{O} \\
& \mathrm{Ti}^{2+} \cdot \mathrm{Si}+\mathrm{H}_{2} \mathrm{O} \rightarrow \mathrm{Ti}-\mathrm{O}-\mathrm{Si}+\mathrm{H}_{2}
\end{aligned}
$$

- - oxygen vacancy.

The release of atomic oxygen from $\mathrm{Ti}-\mathrm{O}-\mathrm{Ti}$ bonds leads to the formation of two $\mathrm{Ti}^{3+}$ cations, separated by oxygen vacancy in the reactions of homolytic cleavage of Ti-O bonds. Such system aims to restoring the initial, stable surface structure of $\mathrm{TiO}_{2}$, and in reaction with water, it reconstructs the oxygen bridge whilst liberating a hydrogen molecule $-\mathrm{H}_{2}$.

In the case of titania-silica carriers in the $\mathrm{Ti}-\mathrm{O}-\mathrm{Si}$ bridge, only the $\mathrm{Ti}^{4+}$ cation is able to take in the electrons resulting from the homolytic splitting of the Ti-O and $\mathrm{Si}-\mathrm{O}$ bonds and the oxygen vacancy has adjacent $\mathrm{Ti}^{2+}$ and $\mathrm{Si}^{4+}$ cations.

$\mathrm{Ti}^{2+}$ cations represent stronger reducing agents than $\mathrm{Ti}^{3+}$ cations and they release hydrogen from the water molecule more effectively. Therefore, titania-silica gels are more active in this reaction.

The above described data on the acidity of investigated titania-silica gels and the proposed surface structure of rhodium complexes: a, b and c - Fig. 2 were used for proposing the course of the photolytic water splitting into a hydrogen molecule $-\mathrm{H}_{2}$ and atomic oxygen $-\mathrm{O}$, in the presence of a photocatalyst containing $50 \% \mathrm{TiO}_{2}$ (Fig. 3):

The rhodium ion $[\mathrm{I}]$ in the complex was linked by a $\sigma$-bond with the hydroxyl group and by co-ordination bonds with three surface oxygen anions of the carrier. In the presented rhodium complexes in Fig. 3, the coordination ligands were removed and appear as: HO-Rh for the sake of simplicity.

The previously presented activity of the carriers applied on rhodium complexes ensured their stability. The complexes must be properly activated in order to enter the photocatalytic cycle of water splitting.

In transition metal complexes, the energy in the UV waverange causes electrons to travel from the highest-occupied molecular orbitals in the transition metal ions to the lowest orbitals with no electrons, thus producing excited ions. 


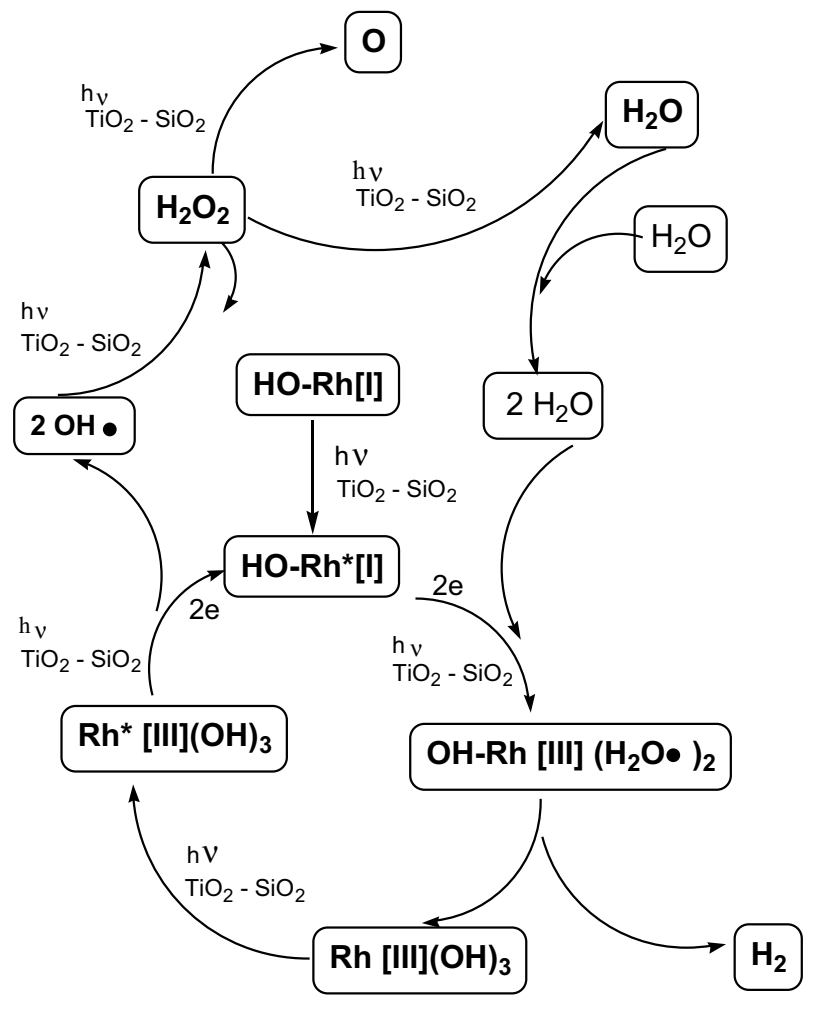

Fig. 3 Proposed mechanism of the water photospling reactin on studied rhosium catalysts

In the Wilkinson-type catalysts, such as $\mathrm{Rh}[\mathrm{I}]$ complexes, as reported earlier, the cleavage of one Rh-O-carrier bond must take place to ensure two vacant orbitals for the formation of the $\mathrm{Rh}[\mathrm{III}]$ octahedron.

The electrons located on the s- and p-atomic orbitals of metal ions and ligands form molecular orbitals with the lowest energy values for their complexes, while those originating from $\mathrm{p}$ atomic orbitals are characterized by a higher energy. Molecular orbitals of nd-electrons have even higher energy and are identical to the d-atomic orbitals of a specific metal ion. Each of these orbitals can split into orbitals of different energy value depending on the structure of the complex, the type of ligands and the energy absorbed [41].

Thus, these two effects: the interaction of the carriers used and the UV radiation of $\lambda \geq 370 \mathrm{~nm}$, produced appropriately activated rhodium ions, which initiated the water splitting reaction run and ensured the subsequent stages of this reaction.

The resulting activated rhodium complexes have been presented in the diagram as $\mathrm{HO}-\mathrm{Rh} *[\mathrm{I}]$ and $\mathrm{HO}-\mathrm{Rh} *[\mathrm{III}]$.

The whole cycle of the investigated photolytic water reaction consists of two stages. In the first "hydrogen" step, in total hydrogen and two hydroxyl radicals are released from two water molecules complexed with rhodium ions. In the other 
"oxygen" step, atomic oxygen and water are obtained from two hydroxyl radicals via the obtained hydrogen peroxide.

The first stage of photolytic water splitting reaction starts with the conversion of the surface complex of rhodium [I] to rhodium [III] and is of an oxidizing addition character.

It consists of the following sub-steps;

- The $\mathrm{Rh}^{*}[\mathrm{I}]$ complex incorporates two water molecules with no effect on the level of oxidation of rhodium ion;

- Two electrons from the $4 d$-molecular orbital of the rhodium ion [I]: $\left.b_{1 g(x 2-y 2)}\right)$ are transferred onto antibonding molecular orbitals: $2 b_{2}{ }^{*}$, two complexed water molecules, this is facilitated by oxygen donor ligands of the carrier, rhodium [III] being already a rhodium ion.

- The interorbital reaction of electrons with protons in the $\mathrm{OH}$ groups of complexed $\mathrm{H}_{2} \mathrm{O}$ molecules, yielding two hydrogen atoms and two $\mathrm{OH}^{-}$groups:

$$
2 \mathrm{e}^{-}+2 \mathrm{H}-\mathrm{O}-\mathrm{H} \rightarrow 2 \mathrm{H}+2 \mathrm{HO}^{-}
$$

- Dimerization of two hydrogen atoms to $\mathrm{H}_{2}$ :

$$
2 \mathrm{H} \rightarrow \mathrm{H} 2
$$

- Two $\mathrm{OH}^{-}$groups become incorporated to $\mathrm{Rh}[\mathrm{III}]$ already formed.

These intermediate stages are related to the reconfiguration of molecular orbitals of rhodium and water molecules.

In the case of the rhodium complex [I] studied, which is a flat square, the molecular orbital diagram for such complexes is as follows [41]: 


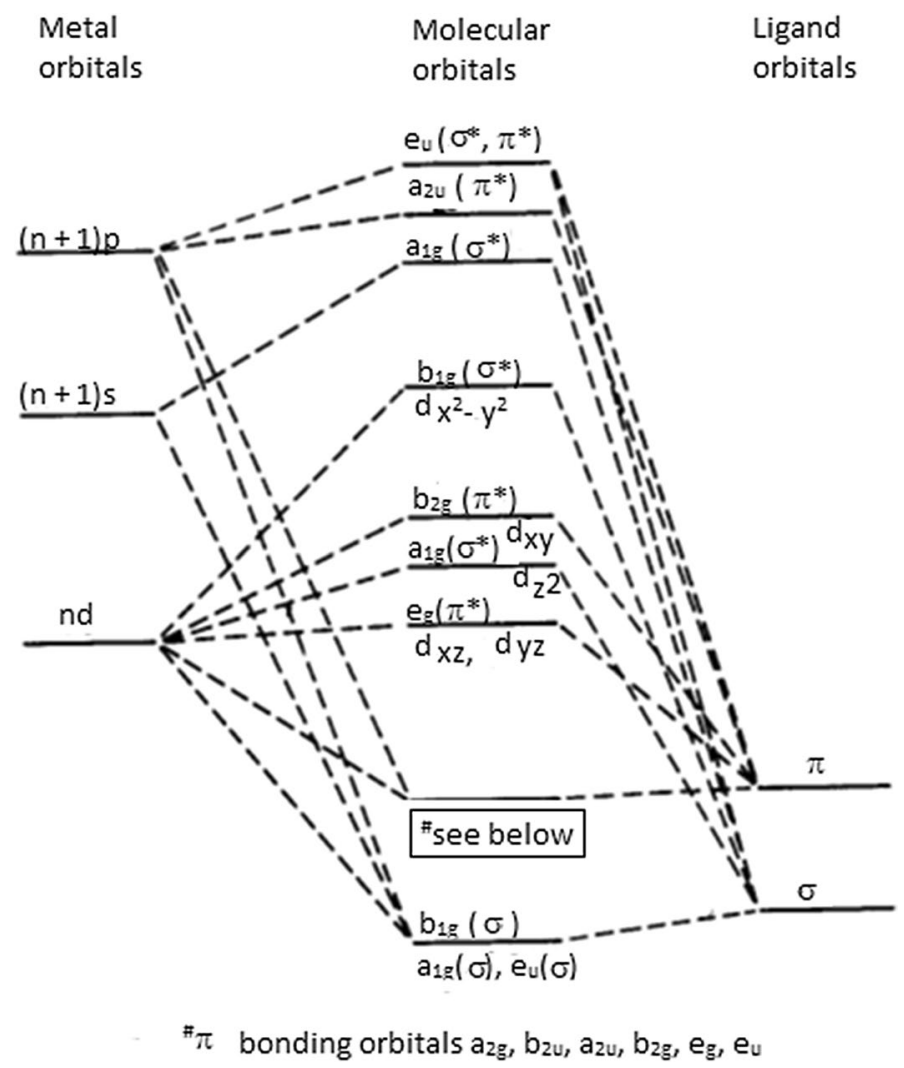

The bonding atomic $(n+1)$ s metal orbitals and $\sigma$ - ligand bonds form the lowest orbitals having a comparable energy, while the molecular orbitals from the binding $(n+1) p$ metal orbitals $(n+1) p$ and $\pi$ ligands also have the same energy, however they are already granted the increased energy (Fig. 4).

Molecular nd-orbitals appear even higher; they are identical to metal nd-orbital and their mutual position is typical for flat square structure metal complexes. Antibonding orbitals of metal and ligand specific orbitals are located on upper position.

Electron d-orbitals configuration and their mutual energy values of the investigated surface $\mathrm{L}_{4} \mathrm{Rh}[\mathrm{I}]$ complex, where rhodium ion is bound to three surface oxygen ligands ( $\pi$-bonding) and to one hydroxyl group ( $\sigma$-bonding):

$\mathrm{L}_{4} \mathrm{Rh}[\mathrm{I}]: 4 \mathrm{~d}^{8} \mathrm{~d}_{\mathrm{zx}}{ }^{2}=\mathrm{d}_{\mathrm{zy}}{ }^{2}<\mathrm{d}_{\mathrm{z} 2}{ }^{2}<\mathrm{d}_{\mathrm{xy}}{ }^{2} \ll \mathrm{d}_{\mathrm{x} 2}-\mathrm{y} 2^{\mathrm{o}}$ (components of higher MO orbitals).

$5 s^{2} 6 p^{6}$ (component of lower MO orbitals).

$$
\sigma \mathrm{OH} 3 \pi \mathrm{O}
$$

$\mathrm{L}=\sigma$-ligands $\mathrm{OH}$ or $\pi \mathrm{O}$ surface ligands.

Electron configuration $\mathrm{L}_{4} \mathrm{Rh}[\mathrm{I}]+$ exposition to UV light - transfer of 2 elektrons from $\mathrm{d}_{\mathrm{xy}}$ onto $\mathrm{d}_{\mathrm{x} 2-\mathrm{y} 2}[34,35,42]$ : 


$$
\begin{gathered}
\mathrm{L}_{4} \mathrm{Rh}[\mathrm{I}]+\mathrm{UV}: 4 \mathrm{~d}^{8}-\mathrm{d}_{\mathrm{zx}}{ }^{2}=\mathrm{d}_{\mathrm{zy}}{ }^{2}<\mathrm{d}_{\mathrm{z} 2}{ }^{2}<\mathrm{d}_{\mathrm{xy}}{ }^{\mathrm{o}} \ll \mathrm{d}_{\mathrm{x} 2-\mathrm{y} 2}{ }^{2} . \\
5 \mathrm{~s}^{2} 6 \mathrm{p}^{6} \\
\sigma \mathrm{OH} 3 \pi \mathrm{O}
\end{gathered}
$$

Electron configuration $\mathrm{L}_{4} \mathrm{Rh}[\mathrm{I}]+\mathrm{UV}^{*}$ and deletion of oxygen carrier ligand.

$$
\begin{gathered}
* \mathrm{~L}_{4}-\mathrm{L} \rightarrow \mathrm{L}_{3} \\
\mathrm{~L}_{2} \mathrm{Rh} *[\mathrm{I}]+\mathrm{UV}-\mathrm{L}: 4 \mathrm{~d}^{8}-\mathrm{d}_{\mathrm{zx}}^{2}=\mathrm{d}_{\mathrm{zy}}^{2}<\mathrm{d}_{\mathrm{z} 2}^{2}<\mathrm{d}_{\mathrm{xy}}^{\mathrm{o}} \ll \mathrm{d}_{\mathrm{x} 2-\mathrm{y} 2}^{2} \\
5 \mathrm{~s}^{2} 6 \mathrm{p}^{4} 6_{\mathrm{p}}^{\mathrm{o}} \\
\sigma \mathrm{OH} 2 \pi \mathrm{O}
\end{gathered}
$$

Bonding of $\mathrm{H}_{2} \mathrm{O}$ to $\mathrm{L}_{3} \mathrm{Rh}[\mathrm{I}]$ with no effect on rhodium ion oxidation.

$$
\begin{gathered}
\mathrm{L}_{2} \mathrm{Rh} *[\mathrm{I}]+\mathrm{UV}: 4 \mathrm{~d}^{8}-\mathrm{d}_{\mathrm{zx}}^{2}=\mathrm{d}_{\mathrm{zy}}^{2}<\mathrm{d}_{\mathrm{z} 2}^{2}<\mathrm{d}_{\mathrm{xy}}^{2} \ll \mathrm{d}_{\mathrm{x} 2-\mathrm{y} 2}^{2} \\
\mathrm{H}_{2} \mathrm{O} \\
5 \mathrm{~s}^{2} 6 \mathrm{p}^{4} 6_{\mathrm{p}}^{2} \\
\sigma \mathrm{OH} 2 \pi \mathrm{O} \mathrm{H}_{2} \mathrm{O}
\end{gathered}
$$

Transfer of two electrons from rhodium ion [I] on two water particles Rh [III] $\mathrm{L}_{3} \mathrm{Rh} *[\mathrm{III}] \mathrm{L}_{3} \mathrm{Rh} *[\mathrm{III}]+\mathrm{UV}: 4 \mathrm{~d}^{8}-\mathrm{d}_{\mathrm{zx}}{ }^{2}=\mathrm{d}_{\mathrm{zy}}{ }^{2}<\mathrm{d}_{\mathrm{z} 2}{ }^{2}<\mathrm{d}_{\mathrm{xy}}{ }^{2} \ll \mathrm{d}_{\mathrm{x} 2-\mathrm{y} 2}{ }^{2+}$
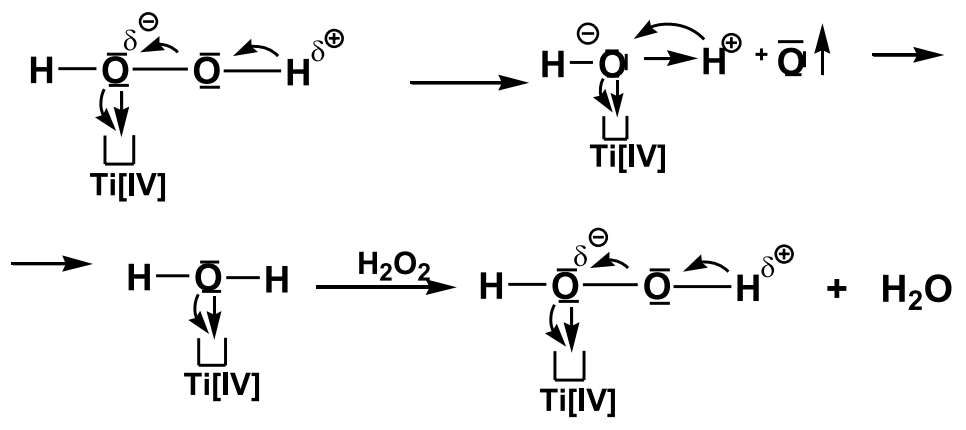

\section{$\sqcup$ - Lewis acidity center on titanium-silica carrier}

Fig. 4 Proposed mechanism 


$$
\begin{gathered}
\mathrm{H}_{2} \mathrm{O} \bullet \\
5 \mathrm{~s}^{2} 6 \mathrm{p}^{4} 6_{\mathrm{p}}^{2} \mathrm{MO} \mathrm{b_{2u }} \\
\sigma \mathrm{OH} 2 \pi \mathrm{O} \mathrm{H}_{2} \mathrm{O} \bullet
\end{gathered}
$$

Formation of octahedral complex $\mathrm{L}_{3} \mathrm{Rh}$ [III] $(\mathrm{OH})_{3}+\mathrm{H}_{2}$, [].

$\mathrm{L}_{3} \mathrm{Rh} *[\mathrm{III}]+\mathrm{UV}: 4 \mathrm{~d}^{8}-\mathrm{d}_{\mathrm{zx}}{ }^{2}=\mathrm{d}_{\mathrm{zy}}{ }^{2}<\mathrm{d}_{\mathrm{z} 2}{ }^{2}<\mathrm{d}_{\mathrm{xy}}{ }^{2} \ll \mathrm{d}_{\mathrm{x} 2-\mathrm{y} 2}{ }^{2+}$

$\mathrm{OH}^{-}$

$$
5 s^{2} 6 p^{4} 6^{2}+\mathrm{H}_{2}
$$

\section{$\sigma \mathrm{OH} 2 \pi \mathrm{O} \mathrm{OH}^{-}$}

The formation of the final octahedral $\mathrm{L}_{3} \mathrm{Rh}[\mathrm{III}](\mathrm{OH})_{3}$ complex through conversion in the co-ordination sphere of the $\mathrm{Rh}[\mathrm{III}]$ complex: transfer of the $\mathrm{OH}^{-}$group

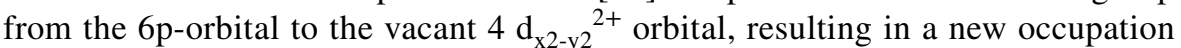
of this orbital $4 \mathrm{~d}_{\mathrm{x} 2-\mathrm{y} 2}{ }^{1+}(\mathrm{OH})$ and the restoration of the $6 \mathrm{p}^{2}-\mathrm{O}$ transfer of the electron from $4 \mathrm{~d}_{\mathrm{xy}}{ }^{2}\left(\mathrm{OH}^{-}\right)$orbital to the $4 \mathrm{~d}_{\mathrm{x} 2-\mathrm{y} 2}{ }^{1+}(\mathrm{OH})$ orbital yielding $4 \mathrm{~d}_{\mathrm{x} 2-\mathrm{y} 2}{ }^{2}(\mathrm{OH})$ and $4 \mathrm{~d}_{\mathrm{xy}}{ }^{2}(\mathrm{OH})$, rearrangement of the orbitals position in terms of energy from $\mathrm{d}_{\mathrm{z} 2}{ }^{2}<\mathrm{d}_{\mathrm{xy}}{ }^{2}(\mathrm{OH})$ to $\mathrm{d}_{\mathrm{z}}{ }^{2}(\mathrm{OH})>\mathrm{d}_{\mathrm{xy}}{ }^{2}$, due to occupation requirements of $\mathrm{d}$-orbitals $\mathrm{d}$ in the octahedron structure:

$$
\mathrm{L}_{3} \mathrm{Rh} \text { [III]: } 4 \mathrm{~d}^{8}-\mathrm{d}_{\mathrm{zx}}{ }^{2}-\mathrm{d}_{\mathrm{xy}}{ }^{2}-\mathrm{d}_{\mathrm{zy}}{ }^{2}<\mathrm{d}_{\mathrm{z} 2}{ }^{2}-\mathrm{d}_{\mathrm{x} 2-\mathrm{y} 2}{ }^{2} \text {. }
$$

$\sigma \mathrm{OH} \sigma \mathrm{OH}$

$$
5 s^{2} 6 p^{6}
$$

\section{$\sigma \mathrm{OH} 3 \pi \mathrm{O}$}

Thus, the resulting rhodium [III] complex has a typical octahedral structure where $\mathrm{d}_{\mathrm{z} 2}{ }^{2}$ and $\mathrm{d}_{\mathrm{x} 2-\mathrm{y}^{2}}{ }^{2}$ orbitals occupy axial positions, whilst the lower energy orbitals: $\mathrm{d}_{\mathrm{zx}}{ }^{2}-\mathrm{d}_{\mathrm{xy}}{ }^{2}-\mathrm{d}_{\mathrm{zy}}{ }^{2}$ occupy equatorial positions.

It should be noted that this stage is formally corresponding to the reaction of water with metals of redox potential above zero. The example of such a reaction is the reaction of metallic sodium with water leading to the release of hydrogen and yielding appropriate hydroxide. In order to achieve the structure of neon, the sodium atom releases an electron, which needs to shift to water orbitals and evoke conversions in this reaction, as presented in reactions 10 and 11.

As regards the study of organometallic complexes with hydroxyl ligands, Piers W. [44] noted that if a metal ion in the $\mathrm{M}^{\mathrm{n}}$ oxidation state bound two water molecules while releasing a hydrogen molecule to form a complex with the $\mathrm{M}^{2+}(\mathrm{OH})_{2}$ -group (oxidative addition stage), then in the reductive elimination hydrogen 
peroxide $-\mathrm{H}_{2} \mathrm{O}_{2}$ would be produced when exposed to UV light, with the restoration of the original complex with the $-\mathrm{M}^{\mathrm{n}}$ ion.

In our case, there are three hydroxyl groups in the trihydroxy rhodium [III] obtained in the oxidative addition step, and hence these two can take part in the postulated reductive elimination.

The formation of hydrogen peroxide in the investigated reaction should take place through the following routes. The $\mathrm{Rh}(\mathrm{OH})_{3}$ obtained is a stable molecule and $\mathrm{Rh}$ [III] ion must be activated to the $\mathrm{Rh}^{*}[\mathrm{III}]$ ion for catalytic conversion. It occurs immediately, as the catalytic system is continuously exposed to UV radiation. The transfer of electrons to $\mathrm{Rh}^{*}[\mathrm{III}]$ cation from two hydroxyl ligands formed in the oxidative addition step needs to take place through the known homolytic cleavage of $\sigma$ - metal-ligand [] bonds, i.e. homolytic cleavage of two $\mathrm{Rh} *(\mathrm{OH})$ bonds resulting in the initial rhodium complex [I] and 2 hydroxyl radicals, in the examined case-reaction 12 .

$$
\mathrm{HO}-\mathrm{Rh}^{*} \underset{\mathrm{OH}}{-} \longrightarrow \mathrm{OH}-\mathrm{Hh}^{*} \bullet+2 \bullet \mathrm{OH} \equiv \mathrm{HO}-\mathrm{Rh}^{*}[\mathrm{I}]+2 \bullet \mathrm{OH}
$$

This process should be applied to hydroxyl groups in the axial positions of $\mathrm{d}_{\mathrm{z} 2}$ and $4 \mathrm{~d}_{\mathrm{x} 2-\mathrm{y} 2}$ orbitals, because, as previously described, octahedral complexes of transition metal with $\mathrm{d}^{6}$ electron configuration are subjected to the Jahn-Teller effect, i.e. elongation of the bonds the metal axial ligand and shortening of the bonds the metal-equatorial ligand bonds. This effect is facilitated by donor ligands as well as the energy contributed by UV radiation.

After the departure of hydroxyl radicals on $4 \mathrm{~d}_{\mathrm{z} 2}$ and $4 \mathrm{~d}_{\mathrm{x} 2-\mathrm{y} 2}$ orbitals, one electron will remain i.e. $4 \mathrm{~d}_{\mathrm{z} 2}{ }^{1}$ and $4 \mathrm{~d}_{\mathrm{x} 2-\mathrm{y} 2}{ }^{1}$ and, for the final energy system of the orbitals to assume a plane square configuration, the electron from $4 \mathrm{~d}_{\mathrm{x} 2-\mathrm{y} 2}{ }^{1}$ orbital will transfer to $4 \mathrm{~d}_{\mathrm{z} 2}$ orbital, which will assume $4 \mathrm{~d}_{\mathrm{z} 2}{ }^{2}$ electron configuration and will lose the energy by positioning itself below the $4 d_{x y}$ orbital whose energy will increase, however the energy of vacant orbital $4 \mathrm{~d}_{\mathrm{x} 2-\mathrm{y} 2}{ }^{\mathrm{o}}$ will increase even more.

These processes will be supported by donor ligands and UV radiation.

This stage completes the "hydrogen" cycle with the interaction of rhodium ions that create $\mathrm{Rh}[\mathrm{I}] \mathrm{Rh}[\mathrm{III}] \mathrm{Rh}[\mathrm{I}]$ cycle, where hydrogen molecule $=\mathrm{H}_{2}$ was released from two molecules of complexed water on the rhodium ion [I], and at the same time this step constitutes the beginning of "oxygen" cycle, where atomic oxygen $=\mathrm{O}$ and water returning to the cycle, will be released from two hydroxyl radicals.

The cycle runs, as follows: the first step invovles the dimerization of hydroxyl radicals to hydrogen peroxide, reaction 13 :

$$
2 \cdot \mathrm{OH}+\mathrm{h} v \rightarrow \mathrm{H}_{2} \mathrm{O}_{2}
$$

The rate constant of this reaction during exposure to UV light is $5.2 \times 10^{9} 1 / \mathrm{Ms}$, where the rate constant of the reverse reaction:

$$
\mathrm{H}_{2} \mathrm{O}_{2}+\mathrm{h} v \rightarrow 2 \cdot \mathrm{OH}
$$

amounts to $3.07 \times 10^{-5} 1 / \mathrm{Ms}[46]$. 
These data demonstrate that the formation of hydroxyl radicals in reaction 12 swiftly leads to the formation of hydrogen peroxide, which, in examined case, quickly degenerates to atomic oxygen and water on the surface of the $50 \%$ Ti photocatalyst, where the surface of the free titanium silica phase covers $99 \%$ second study reaction 14 .

$$
\mathrm{H}_{2} \mathrm{O}_{2} \rightarrow \mathrm{H}_{2} \mathrm{O}+\mathrm{O}
$$

Such a process has also been described by S. Imamura et al. [15], as reported earlier, for titanium-silica gel of the same composition. The activity of these gels has been attributed to the presence of acid centers and Ti-O-Si bonds.

The carriers of tested photocatalysts, also with the same quantity of $\mathrm{TiO}_{2}$, exhibit the highest acidity, whereas the rhodium [I] complexes deposited on this carrier turn the most effective in the photolytic water splitting reaction. These properties are also linked to the presence of the Ti-O-Si grouping. As discussed previously, Ti [IV] ion exhibits a relatively strong Lewis acidity in that grouping.

The "oxygen" cycle:

$$
2 \cdot \mathrm{OH} \rightarrow \mathrm{H}_{2} \mathrm{O}_{2} \rightarrow \mathrm{H}_{2} \mathrm{O}+\mathrm{O}
$$

This is irreversible, as its end products involve a thermodynamically stable water molecule and atomic oxygen which, after dimerization to $\mathrm{O}_{2}$, leaves the reaction as a gas.

Hydrogen peroxide exhibits Brønsted acidity [47], which means that one of the $\mathrm{O}-\mathrm{H}$ bonds is polarized, so that a partial positive charge is found on the hydrogen, while a partial negative charge is located on the titanium ion of the other $\mathrm{OH}$ group. Under favourable conditions, this leads to the dissociation of hydrogen as a proton.

The role of oxygen being released from the ionized peroxide molecule in the presence of titanium silica gel can be presented as follows: Diagram 2.

The ionized hydrogen peroxide molecule becomes complexed on the surface $\mathrm{Ti}$ [IV] ion having the said Lewis acidity, through the oxygen ion with a partial negative charge. This entails further ionization of the peroxide, yielding a proton $-\mathrm{H}^{+}$, while the electrons obtained by the adjacent oxygen from $\mathrm{O}-\mathrm{H}$ bond release it as the atomic oxygen. At this stage, the complexed oxygen with the acid center of the carrier affords a negative charge which forms a water molecule by binding a liberated proton. Water is complexed by an acid center, however a partially ionized hydrogen peroxide molecule will push it away from this center. This launches another cycle of releasing atomic oxygen and water, which returns to the entire water splitting cycle.

Thus, this pathway starting from hydroxyl radicals to atomic oxygen and water, and requiring the specific conditions as described, adds to the stoichiometry of the photolytic water splitting reaction on the catalysts under study.

If the "hydrogen" cycle yields hydrogen molecule- $\mathrm{H}_{2}$, then the "hydroxyl radical conversion" cycle leads to atomic oxygen. In order to maintain a constant standard balance of water splitting reaction, both cycles must run at the same speed.

The obtained findings and literature data allow to formulate the following conclusions: 
Initiation of the run of both cycles needs the activation of stable rhodium [I] and rhodium [III] complexes through the interaction of $40-50 \mathrm{~mol} \% \mathrm{TiO}_{2}$ carriers and UV radiation with a wavelength of $\geq 370 \mathrm{~nm}$.

Furthermore, both cycles require the presence of $40-50 \mathrm{~mol} \% \mathrm{TiO}_{2}$ carriers the "hydrogen" cycle as the carrier of the rhodium complexes, the "oxygen" cycle - as the catalyst for the degradation of hydrogen peroxide. These carriers contain the highest number of Ti-O-Si bonds linking $\mathrm{TiO}_{2}$ octahedras with $\mathrm{SiO}_{2}$ tetrahedra;

Lewis acid centers of $\mathrm{H}_{\mathrm{o}}$ strength, appearing only on the catalysts containing 40-50 $\mathrm{mol} \% \mathrm{TiO}_{2}$ ensure effective and selective degradation of hydrogen peroxide into oxygen and water.

\section{Conclusions}

- Titanium-silica gel obtained, containing 40-50 mol\% $\mathrm{TiO}_{2}$ is the most active carrier of rhodium complexes in the investigated photolytic water splitting reaction;

- These gels exhibit the highest acidity determined by $\mathrm{H}_{\mathrm{o}}$ coefficient;

- Photolytic splitting of $\mathrm{RhCl}_{3}$ applied to investigated gels using UV light of $\lambda \geq 370 \mathrm{~nm}$, has led to the formation of rhodium hydroxy complexes of various degrees of oxidation: $\mathrm{Rh}[\mathrm{I}]$ complexes appeared with $\mathrm{SiO}_{2}$ and gels 10-90 mol\% $\mathrm{TiO}_{2}$ as carriers, while $\mathrm{Rh}$ [III] complexes were formed on gels of 60-100 mol\% $\mathrm{TiO}_{2}$;

- Rhodium complexes occupy only $\leq 0.02 \%$ of the surface of titania-silica carriers;

- The photolytic water splitting reaction, according to our proposal, consisted of two cycles: in the first "hydrogen" cycle, running only on rhodium complexes, in line with a typical mechanism of oxidative addition and reductive elimination, a hydrogen molecule and two $\mathrm{OH}$ radicals are released and the initial active rhodium [I] complex is recreated. In the second cycle, the hydroxyl radicals become converted, in the presence of Lewis acid centers appearing on the surface of 40-50\% Ti carriers, into atomic oxygen and water is returning to the circulation;

- Both "hydrogen" and "oxygen" cycles must run at the same rate so as to maintain the stoichiometry of $\mathrm{H}_{2} \mathrm{O} \rightarrow \mathrm{H}_{2}+\mathrm{O}$ reaction;

- Photocatalytically active inorganic rhodium complexes and titania-silica gels as well as the aqueous environment of the reaction ensure the absence of organic compounds in the reaction environment and thus evoke the stoichiometric run of the photolytic water splitting reaction to hydrogen and oxygen - no reaction of hydroxyl radicals with organic compounds;

- The presence of two types of rhodium and surface catalytic centers of the carrier was necessary to run photolytic water splitting reaction, as well as the specific addition of energy: interaction on rhodium ions by carriers: 40 - and in particular, $50 \mathrm{~mol} \%$ of $\mathrm{TiO}_{2}$, and the energy contributed by UV light of $\lambda \geq 370 \mathrm{~nm}$. 
Open Access This article is licensed under a Creative Commons Attribution 4.0 International License, which permits use, sharing, adaptation, distribution and reproduction in any medium or format, as long as you give appropriate credit to the original author(s) and the source, provide a link to the Creative Commons licence, and indicate if changes were made. The images or other third party material in this article are included in the article's Creative Commons licence, unless indicated otherwise in a credit line to the material. If material is not included in the article's Creative Commons licence and your intended use is not permitted by statutory regulation or exceeds the permitted use, you will need to obtain permission directly from the copyright holder. To view a copy of this licence, visit http://creativecommons.org/licen ses/by/4.0/.

\section{References}

1. Hashimoto K, Irie H, Fujishima A (2005) $\mathrm{TiO}_{2}$ photocatalysis: a historical overview and future prospects. Jap J Appl Phys 44(12R):8269-8285

2. Nakata K, Fujishima A (2012) $\mathrm{TiO}_{2}$ photocatalysis design and applications. J Photochem Photobiol C Photochem Rev 13(3):169-189

3. Chen H, Nanayakkara ChE, Grassian VH (2012) Titanium dioxide photocatalysis in atmospheric chemistry. Chem Rev 112:5919-5948

4. Tiana J, Zhaoa ZH, Kumarb A, Boughtonc RI, Liua H (2014) Recent progress in design synthsis and applications of one-dimensional $\mathrm{TiO}_{2}$ nanostructured surface heterostructures: a review. Chem Soc Rev 43(20):6920-6937

5. Realpe A, Núñez D, Carbal I, Acevedo MT, De Avila G (2015) Preparation and characterization of titanium dioxide photoelectrodes for generation of hydrogen by photoelectrochemical water splitting. IJET 7(2):753-759

6. Aung SH, Zhao L, Nonomura K, Oo TZ, Zakeeruddin SM, Vlachopoulos N, Sloboda T, Svanström S, Cappel UB, Hagfeldt A, Grätzel M (2019) Toward an alternative approach for the preparation of low-temperature titanium dioxide blocking underlayers for perovskite solar cells. J Mater Chem A 7:10729-11078

7. Liu G, Du K, Xu J, Chen G, Gu M, Yang CH, Wang K, Jakobsen H (2017) Plasmon-dominated photoelectrodes for solar water splitting. J Mater Chem A 5:4233-4253

8. Atabaev TSh, Lee DH, Hong NH (2017) Fabrication of $\mathrm{TiO}_{2} / \mathrm{CuO}$ photoelectrode with enhanced solar water splitting activity. Funct Mater Lett 10(6):1750084

9. Acar C, Dincerm I (2014) Comparative assessment of hydrogen production methods from renewable and non-renewable sources. Inter Hydrog Energy 39:1-12

10. Humayun M, Raziq F, Khan A, Luo W (2018) Modification strategies of $\mathrm{TiO}_{2}$ for potential applications in photocatalysis: a critical review. J Green Chem Lett 11(2):86-102

11. Xu A-W, GaoYuan L-Q (2002) The preparation, characterization, and their photocatalytic activities of rare-earth-doped $\mathrm{TiO}_{2}$ nanoparticles. J Catal 207(2):151-157

12. Shankar MV, Palanichamy M, Arabindoo B, Bahnemann DW, Murugesan V, Sakthivel S (2004) Enhancement of photocatalytic activity by metal deposition: characterisation and photonic efficiency of $\mathrm{Pt}, \mathrm{Au}$ and $\mathrm{Pd}$ deposited on $\mathrm{TiO}_{2}$ catalyst. Water Res 38(13):3001-3008

13. Gaidau C, Petica A, Ignat M, Iordache O, Ditu LM, Ionescu M (2016) Enchanced photocatslysts on $\mathrm{Ag}-\mathrm{TiO}_{2}$ and $\mathrm{Ag}-\mathrm{N}-\mathrm{TiO}_{2}$ nanoparticles for multifunctional lather surface coating. Open Chem 14:383-392

14. Nguyen TV, Yang OB (2003) Photoresponse and AC impedance characterization of $\mathrm{TiO}_{2}-\mathrm{SiO}_{2}$ mixed oxide for photocatalytic water decomposition. Catal Today 87:69-75

15. Imamura S, Ishida S, Tarumoto H, Saito Y (1993) Effect of the composition of titania-silica on its physical and catalytic properties. J Chem Soc Faraday Trans 89:757-762

16. Gao X, Wachs IE (1999) Titania - silica as catalysts: molecular structural characteristics and physico-chemical properties. Catal Today 51:233-254

17. Hendrix Y, Lazaro A, Yu QL, Brouwers J (2015) Titania-silica composites: a review on the photocatalytic activity and synthesis methods. World J Nano Sci Eng 5:161-177

18. Mohamed MM, Salama TM, Yamaguchi T (2002) Synthesis, characterization and catalytic properties of titania-silica catalysts. Colloids Surf A Phys Chem Eng Asp 207:25-32 
19. Dutoit DCM, Göbel U, Schneider M, Baiker A (1996) Titania-silica mixed oxides: V. effect of solgel and drying conditions on surface properties. J Catal 164(2):433-439

20. Doolin K, Alerasool S, Zalewski DJ, Hoffman JF (1994) Acidity studies of titania-silica mixed oxides. Catal Lett 25:209-223

21. Lehn JM, Sauvage JP, Zlessel R, Hilaire L (1982) Water photolysis by UV irradiation of rhodium loaded strontium titanate catalysts relation between catalytic activity and nature of the deposit from combined photolysis and ESCA studies. Isr J Chem 22(2):168-172

22. Lin Y-S, Lin H-P, Mou C-Y (2004) A simple synt hesis of well-ordered super-microporous aluminosilicate. Microporous Mesoporous Mater 76:203-208

23. Tsega M, Dejene FB (2017) Influence of acidic $\mathrm{pH}$ on the formulation of $\mathrm{TiO}_{2}$ nanocrystalline powders with enhanced photoluminescence property. Heliyon 3:0246

24. Lutsko JF (2019) How crystals form A theory of nucleation pathways. Sci Adv 5(4):7399

25. Tanabe K (1971) Solid acids and bases: their catalytic properties. Elsevier, Cambridge

26. National Library of Medicine. https://pubchem.ncbi.nlm.nih.gov/compound/Thymol-blue. Accessed 21 January 2021

27. Pearson RG (1963) Hard and soft acids and bases. J Am Chem Soc 85(22):3533-3539

28. Strayer E, Binz JM, Tanase M, Shahri SMK, b Sharma R, Rioux RM, Mallouk TE, (2014) Interfacial bonding stabilizes rhodium and rhodium oxide nanoparticles on layered $\mathrm{Nb}$ - and Ta-oxide supports. J Am Chem Soc 136(15):5687-5696

29. Fujiwara H, Ogasawara Y, Kotani M, Yamaguchi K, Mizuno N (2008) Supported rhodium hydroxide catalyst: preparation, characterization, and scope of the synthesis of primary amides from aldoximes or aldehydes. Chem Asian 3(8-9):1715-1721

30. Kölle U, Grützel M (1987) Organometallic Rhodium (III) complexes as catalysts for the oreduction of protons to hydrogen on colloidal $\mathrm{TiO}_{2}$. Angev Chem Eng Ed 26(6):567-570

31. Kristoffersen $\mathrm{HH}$, Shea JE, Metiu $\mathrm{H}$ (2015) Catechol and $\mathrm{HCl}$ adsorption on $\mathrm{TiO}_{2}(110)$ in vacuum and at the water- $\mathrm{TiO}_{2}$ interface. J Phys Chem Lett 6(12):62277-62281

32. Osborn JA, Wilkinson G, Mrowca JJ (1967) Tris (triphenylphosphine) halorhodium (I). Inorg Synth 10:67-71

33. Cramer R, McCleverty A, Bray J (1974) Di- $\mu$-chlorotetrakis (ethylene) dirhodium(I) 2,4-pentanedionato bis (ethylene) rhodium (I) and di- $\mu$-chlorotetracarbonyldirhodium (I). Inorg Synth 15:14-18

34. Cotton FA, Wilkinson G (1980) Advanced inorganic chemistry. A comprehensive text, 4th edn. John Wiley and Sons, New York

35. Jean Y (2005) Molecular orbitals of transition metal complexes. Oxford University Press, Oxford, England

36. Ibers JA, Snyder RG (1962) Crystal structure of the dimer of rhodium 1,5-cycloodtadiene. Acta Crystal 15:923-930

37. Hull EA, West AC, Pestovsky O, Kristian KE, Ellern A, Dunne JF, Carraher JM, Bakac A, Windus TL (2015) UV-visible spectroscopy of macrocyclic alkyl, nitrosyl and halide complexes of cobalt and rhodium. Experiment and calculation. Dalton Trans 44:3811-3816

38. Šušnjar N (2006) Towards rhodium and iridium oxo complexes, Dissertation, Hamburg

39. Diebold U (2003) The surface of titanium dioxide. Surf Sci Rep 48:4853-5229

40. Snyder LR, Ward JW (1966) The surface structure of porous silicas. J Phys Chem 70(12):3941-3952

41. Cotton FA, Wilkinson G (1980) Advenced inorganic chemistry. A comprehensive text, 4th edn. John Wiley and Sons, New York

42. CH2501-TransitionMetalsChemistry. Eli Zysman-Colman. http://www.zysmancolman.com/cours es/ch2501/CH2501\%20Transition\%20Metals\%20Chemistry\%20Course\%20Notes.pdf. Accessed 21 January 2021

43. Kohl SW, Weiner L, Schwartsburd L, Konstantinovski L, Shimon LJ, Ben-David Y, Iron MA, Milstein D (2009) Consecutive thermal $\mathrm{H}_{2}$ and light-induced $\mathrm{O}_{2}$ evolution from water promoted by a metal complex, science 324 5923: 74-7 splitting. Organometallics 30:13-16

44. Piers WE (2011) Future trends in organometallic chemistry: organometallic approaches to water splitting. Organometallics 30(1):13-16

45. Strunk J, Vining WC, Bell AT (2010) Study of oxygen vacancy formation and annihilation in submonolayer coverages of $\mathrm{TiO}_{2}$ dispersed on MCM-48. J Phys Chem C 114:16937-16945

46. Fujita T, Zhang L, Dodbiba G, Wnh JW, Wei Y, Kurokawa H, Matsul H, Yamamoto Sh, Kawagushi $\mathrm{H}$ (2017) Production of the hydroxyl radical and removal of formalede by calcined tuff powder and tile. Period Polytech Chem Eng 61:3236-3245 
47. National Library of Medicine. https://pubchem.ncbi.nlm.nih.gov/compound/Hydrogen-peroxide. Accessed 21 January 2021.

Publisher's Note Springer Nature remains neutral with regard to jurisdictional claims in published maps and institutional affiliations. 